\title{
Amygdalin inhibits the growth of renal cell carcinoma cells in vitro
}

\author{
EVA JUENGEL ${ }^{1}$, ANITA THOMAS ${ }^{1}$, JOCHEN RUTZ ${ }^{1}$, JASMINA MAKAREVIC ${ }^{1}$, IGOR TSAUR ${ }^{1}$ \\ KAREN NELSON $^{2}$, AXEL HAFERKAMP ${ }^{1 *}$ and ROMAN A. BLAHETA ${ }^{1 *}$ \\ Departments of ${ }^{1}$ Urology and ${ }^{2}$ Vascular and Endovascular Surgery, Goethe-University Hospital, \\ D-60590 Frankfurt am Main, Germany
}

Received October 5, 2015; Accepted December 4, 2015

DOI: $10.3892 / \mathrm{ijmm} .2015 .2439$

\begin{abstract}
Although amygdalin is used by many cancer patients as an antitumor agent, there is a lack of information on the efficacy and toxicity of this natural compound. In the present study, the inhibitory effect of amygdalin on the growth of renal cell carcinoma (RCC) cells was examined. Amygdalin $(10 \mathrm{mg} / \mathrm{ml})$ was applied to the RCC cell lines, Caki-1, KTC-26 and $\mathrm{A} 498$, for $24 \mathrm{~h}$ or 2 weeks. Untreated cells served as controls. Tumor cell growth and proliferation were determined using MTT and BrdU tests, and cell cycle phases were evaluated. Expression of the cell cycle activating proteins cdk1, cdk2, cdk4, cyclin A, cyclin B, cyclin D1 and D3 as well as of the cell cycle inhibiting proteins p19 and p27 was examined by western blot analysis. Surface expression of the differentiation markers E- and N-cadherin was also investigated. Functional blockade by siRNA was used to determine the impact of several proteins on tumor cell growth. Amygdalin treatment caused a significant reduction in RCC cell growth and proliferation. This effect was correlated with a reduced percentage of G2/M-phase RCC cells and an increased percentage of cells in the G0/1-phase (Caki-1 and A498) or cell cycle arrest in the S-phase (KTC-26). Furthermore, amygdalin induced a marked decrease in cell cycle activating proteins, in particular cdk1 and cyclin B. Functional blocking of cdk1 and cyclin B resulted in significantly diminished tumor cell growth in all three RCC cell lines. Aside from its inhibitory effects on growth, amygdalin also modulated the differentiation markers, E- and $\mathrm{N}$-cadherin. Hence, exposing RCC cells to amygdalin inhibited cell cycle progression and tumor cell growth by impairing cdk1 and cyclin B expression. Moreover, we noted that amygdalin affected differentiation markers. Thus, we suggest that amygdalin exerted RCC antitumor effects in vitro.
\end{abstract}

Correspondence to: Dr Eva Juengel, Goethe-University Hospital Department of Urology, Interdisciplinary Science Building, Theodor-Stern-Kai 7, D-60590 Frankfurt am Main, Germany E-mail: eva.juengel@kgu.de

${ }^{*}$ Contributed equally

Key words: amygdalin, cell cycle, cell growth, differentiation marker, renal cell carcinoma

\section{Introduction}

Renal cell carcinoma (RCC) is the most common renal cancer and most aggressive urologic tumor, and its incidence is increasing (1). Approximately $15-20 \%$ of RCC patients already have metastases at diagnosis, while up to $30 \%$ of patients develop metastases during therapy. Once metastasized, the prognosis for patients is poor. Increased knowledge of the molecular modes of action of RCC has contributed to the development of targeted therapies during the last decade, thus improving the outlook for patients in advanced stages of the disease. However, despite therapeutic advances, prognosis for patients with RCC remains poor, with 5-year survival remaining between 5 and $12 \%(2,3)$.

Most patients with advanced RCC wish to actively participate in their battle against cancer and/or to avoid adverse side effects, which often occur during conventional therapy. Many patients, therefore, turn towards complementary and alternative medicine (CAM). More than 50\% of cancer patients in Europe (4) and up to $80 \%$ of cancer patients in the United States (5) use CAM together with or in place of conventional therapy.

Amygdalin (D-mandelonitrile- $\beta$-gentiobioside) is a natural compound which is often used by cancer patients. It is found in the fruit kernels of apricots, peaches, apples and in bitter almonds (6-8). The first studies on amygdalin use by cancer patients came from Russia in the 1840s (9). In the 1920s amygdalin was also administered to cancer patients in the United States (10). In the 1950s a semi-synthetic, chemically different derivate of amygdalin, laetrile, was introduced. After the introduction of laetrile, the terms amygdalin and laetrile were often used synonymously, making it difficult to draw conclusions from studies which did not discriminate between the two compounds (11). In the 1970s amygdalin/leatrile became one of the most popular, non-conventional anticancer treatments. By 1978, approximately 70,000 US cancer patients had used amygdalin (12). The National Cancer Institute (NCI) initiated several studies (13-16) with sobering results. In a summary of the only phase II trial, no substantive benefit was ascribed to amygdalin, whereas several patients with symptoms of cyanide $(\mathrm{HCN})$ poisoning were described (13). However, the quality of this study is questionable since a heterogeneous patient cohort was used, no control groups were included, and a racemate instead of pure amygdalin was used for the i.v. therapy. All official judgement concerning amygdalin has been based on this trial, since no other clinical trial with amygdalin is available. The 
German Federal Institute for Drugs and Medical Devices (BfArM) (http://www.bfarm.de/DE/Home/home_node.html), has also classified amygdalin as a questionable drug, as have counterparts in other countries. Despite the controversy and lack of scientifically sound data on the benefits and risks of amygdalin, many cancer patients use amygdalin $(11,17)$. Thus, to clarify the many questions which remain to be answered on the impact of amygdalin on tumor growth and proliferation, the cell cycle progression and underlying molecular action modes in RCC cells were determined in the present study.

\section{Materials and methods}

Cell cultures and amygdalin treatment. The kidney carcinoma cell lines, Caki-1, KTC-26 and A498 were purchased from LGC Promochem (Wesel, Germany). The cells were grown and sub-cultured in RPMI-1640 medium (obtained from Seromed, Berlin, Germany) supplemented with $10 \%$ FCS, $20 \mathrm{mM}$ HEPES-buffer, $100 \mathrm{IU} / \mathrm{ml}$ penicillin and $100 \mu \mathrm{g} / \mathrm{ml}$ streptomycin at $37^{\circ} \mathrm{C}$ in a humidified atmosphere with $5 \% \mathrm{CO}_{2}$ in an incubator. Sub-cultures from passages 5-24 were selected for use in the experiments. Amygdalin from apricot kernels (Sigma-Aldrich, Taufkirchen, Germany) was freshly dissolved in cell culture medium and was then added to the tumor cells at a concentration of $10 \mathrm{mg} / \mathrm{ml}$ [previously evaluated as optimal concentration (18)] for either $24 \mathrm{~h}$ or 2 weeks (three times a week) to evaluate acute versus chronic treatment. The controls remained untreated. In all experiments in the present study, treated tumor cell cultures were compared to non-treated tumor cell cultures. In order to examine the toxic effects of amygdalin, cell viability was determined by Trypan blue (Gibco/ Invitrogen, Darmstadt, Germany).

Measuring tumor cell growth, proliferation and apoptosis. Cell growth was assessed using the 3-(4,5-dimethylthiazol-2-yl)2,5-diphenyltetrazolium bromide (MTT) dye reduction assay (Roche Diagnostics, Penzberg, Germany). Caki-1 cells (50 $\mu \mathrm{l}$, $1 \times 10^{5}$ cells $/ \mathrm{ml}$ ) were seeded onto 96 -well tissue culture plates. After 24, 48 and $72 \mathrm{~h}, 10 \mu \mathrm{l}$ MTT $(0.5 \mathrm{mg} / \mathrm{ml})$ were added for an additional $4 \mathrm{~h}$. Thereafter, cells were lysed in a buffer containing $10 \% \mathrm{SDS}$ in $0.01 \mathrm{M} \mathrm{HCl}$. The plates were incubated overnight at $37^{\circ} \mathrm{C}, 5 \% \mathrm{CO}_{2}$. Absorbance at $550 \mathrm{~nm}$ was determined for each well using a microplate enzyme-linked immunosorbent assay (ELISA) reader. After subtracting background absorbance, results were expressed as the mean number of cells.

Cell proliferation was measured using a BrdU cell proliferation ELISA kit (Calbiochem/Merck Biosciences, Darmstadt, Germany). Tumor cells, seeded onto 96-well plates, were incubated with $20 \mu \mathrm{l}$ BrdU-labeling solution per well for $8 \mathrm{~h}$, and fixed and detected using anti-BrdU mAb according to the manufacturer's instructions. Absorbance was measured at $450 \mathrm{~nm}$ using a microplate ELISA reader.

In order to evaluate whether tumor cell growth was impaired or reduced due to apoptosis, the expression of Annexin V/propidium iodide (PI) was evaluated using an Annexin V-FITC Apoptosis Detection kit (BD Pharmingen, Heidelberg, Germany). Tumor cells were washed twice with PBS and subsequently incubated with $5 \mu \mathrm{l}$ Annexin V-FITC and $5 \mu \mathrm{l}$ of PI in the dark for $15 \mathrm{~min}$ at room temperature.
Cells were analyzed by flow cytometry using FACSCalibur (BD Biosciences, Heidelberg, Germany). The percentage of apoptotic cells (early and late) in each quadrant was calculated using CellQuest software (BD Biosciences).

Percentage of cells in different cell cycle phases. Cell cycle analysis was carried out on subconfluent cell cultures. Tumor cell populations were stained with PI, using a CycleTEST PLUS DNA Reagent Kit and then subjected to flow cytometry using FACScan (both from Becton-Dickinson, Heidelberg, Germany). From each sample 10,000 events were collected. Data acquisition was carried out using CellQuest software, and cell cycle distribution was calculated using ModFit software (Becton-Dickinson). The number of gated cells in G1, G2/M or $\mathrm{S}$ phases is expressed in percentage form.

Expression of cell cycle regulating proteins. Cell cycle regulating proteins were investigated by western blot analysis. Tumor cell lysates were applied to a 7-15\% polyacrylamide gel (depending on protein size) and electrophoresed for $90 \mathrm{~min}$ at $100 \mathrm{~V}$. The protein was subsequently transferred to nitrocellulose membranes $(1 \mathrm{~h}, 100 \mathrm{~V})$. After blocking with non-fat dry milk for $1 \mathrm{~h}$, the membranes were incubated overnight with monoclonal antibodies directed against the following cell cycle proteins, which were all from BD Biosciences: cdk1 (IgG1, clone 1, dilution 1:2,500; \#610038), cdk2 (IgG2a, clone 55, dilution 1:2,500; \#610146), cdk4 (IgG1, clone 97, dilution 1:250; \#610148), cyclin A (IgG1, clone 25, dilution 1:250; \#611269), cyclin B (IgG1, clone 18, dilution 1:1,000; \#610220), cyclin D1 (IgG1, clone G124-326, dilution 1:250; \#554181), cyclin D3 (IgG2b, clone 1, dilution 1:1,000; \#610280), p19 (IgG1, clone 52/p19, dilution 1:5,000; \#610530), p27 (IgG1, clone 57, dilution 1:500; \#610244). HRP-conjugated goat-antimouse IgG (dilution 1:5,000; \#12-349; Merck Millipore, Temecula, CA, USA) served as the secondary antibody. The membranes were briefly incubated with ECL detection reagent (ECL ${ }^{\mathrm{TM}}$; Amersham/GE Healthcare, München, Germany) to visualize the proteins and then analyzed with the Fusion FX7 system (Peqlab, Erlangen, Germany). $\beta$-actin (dilution 1:1,000; \#A5441; Sigma, Taufenkirchen, Germany) served as the internal control.

Surface expression of $E$ - and $N$-cadherin. Tumor cells were washed in blocking solution (PBS, $0.5 \%$ BSA) and then incubated for $60 \mathrm{~min}$ at $4^{\circ} \mathrm{C}$ with phycoerythrin (PE)-conjugated monoclonal antibodies $(\mathrm{mAB})$ directed against the following: anti-human E-cadherin-PE (mouse IgG2b, clone 180224; \#FAB18381P) and anti-human N-cadherin-PE (rat IgG2a, clone 401408; \#IC1388P) (both from R\&D Systems, Wiesbaden, Germany). E- and N-cadherin surface expression of the RCC cells was then measured by flow cytometry using FACscan [FL-2H (log) channel histogram analysis; $1 \times 10^{4}$ cells/ scan;BD Biosciences] and expressed as mean fluorescence units. Rat IgG2a-PE (clone RG7/1.30; \#558067) or mouse IgG2b-PE (clone 27-35; \#555743) (both from BD Biosciences) served as isotype controls.

Blocking experiments. To determine whether cdk1 and cyclin B impacted tumor cell growth in Caki-1, KTC-26 and A498 cell lines, cells were transfected. Tumor cells $\left(3 \times 10^{5} / 6\right.$-well) were 


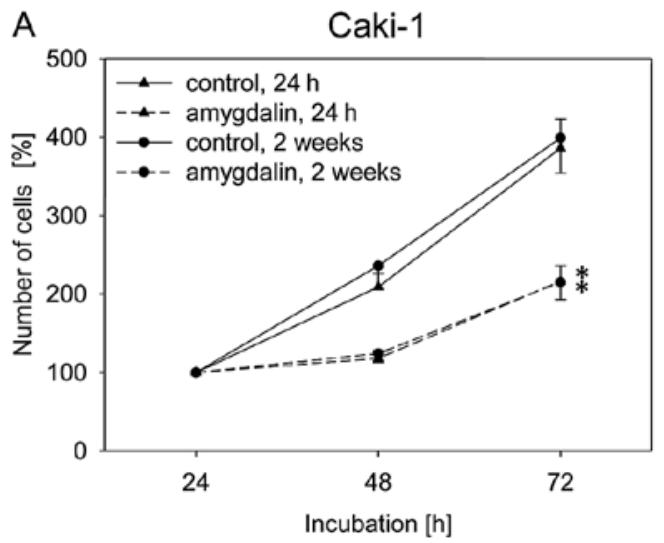

B $\quad$ KTC-26

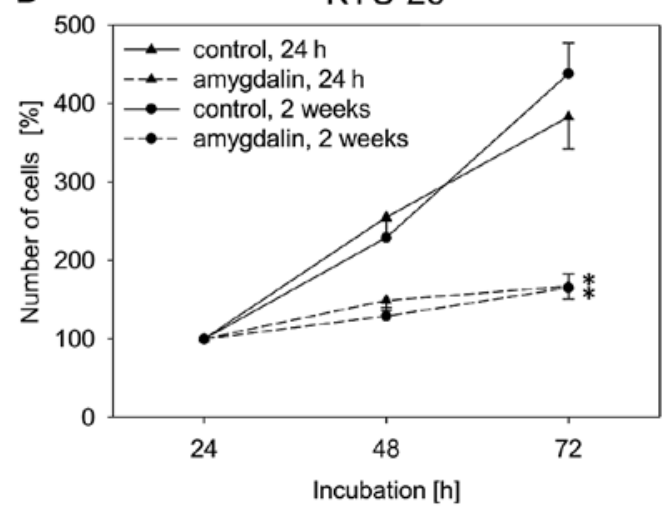

C

A498

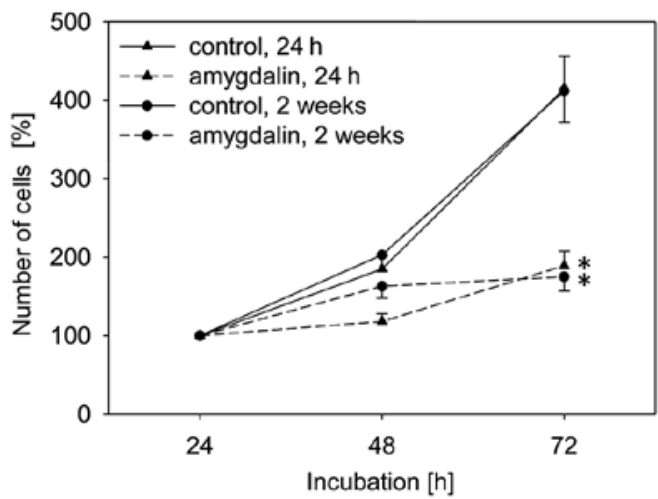

Figure 1. Growth of renal cell carcinoma (RCC) cells, (A) Caki-1, (B) KTC-26 and (C) A498. Cells were treated with $10 \mathrm{mg} / \mathrm{ml}$ amygdalin for $24 \mathrm{~h}$ or 2 weeks Controls remained untreated. Number of cells was set to $100 \%$ after $24 \mathrm{~h}$ incubation. Bars indicate the means \pm standard deviation (SD). " $\mathrm{p} \leq 0.05$ indicates a significant difference to the control. $\mathrm{n}=5$ experiments.

transfected with small interfering RNA (siRNA) directed against cdk1 (Hs_CDC2_10, gene ID: 983, target sequence: AAGGGGTTCCTAGTACTGCAA) or cyclinB(Hs_CCNB1_6, gene ID: 891, target sequence: AATGTAGTCATGGTAAAT CAA) (both from Qiagen, Hilden, Germany), with siRNA/transfection reagent (HiPerFect transfection reagent; Qiagen) at a ratio of 1:6. Non-treated cells and cells treated with $5 \mathrm{nM}$ control siRNA (AllStars Negative Control siRNA; Qiagen) served as controls. Subsequently, tumor cell growth was determined as indicated above.

Statistical analysis. All experiments were performed 3-6 times. Statistical significance was determined by the Wilcoxon-MannWhitney U test. A p-value $<0.05$ was considered to indicate a statistically significant difference.

\section{Results}

Tumor cell growth and proliferation is blocked by amygdalin. Exposure to amygdalin $(10 \mathrm{mg} / \mathrm{ml})$ for $24 \mathrm{~h}$ or 2 weeks resulted in significant and similar degrees of growth inhibition over $72 \mathrm{~h}$ in all three RCC cell lines, Caki-1, KTC-26 and A498, compared to the untreated control cells (Fig. 1). Caki-1, KTC-26 and A498 cell proliferation was also significantly reduced after $24 \mathrm{~h}$ or 2 weeks of amygdalin exposure, compared to the controls (Fig. 2). Antitumor effects in the RCC cells were comparable after $24 \mathrm{~h}$ and 2 weeks of amygdalin treatment (Fig. 2).
Neither apoptosis nor necrosis is induced by amygdalin. Neither significant early or late apoptosis, nor induction of necrosis, was detected after amygdalin administration (data not shown).

Amygdalin alters the percentage of RCC cells in G0/1-, $S$ - and $G 2 / M$-phases. Amygdalin significantly increased the percentage of Caki-1 and A498 cells in the G0/G1-phase and reduced the amount of S- and G2/M-phase cells after $24 \mathrm{~h}$ and 2 weeks (Fig. 3) of exposure, compared to untreated controls. In KTC-26 cells, amygdalin caused the percentage of G2/M-phase cells to significantly decrease, while S-phase cells increased ( $24 \mathrm{~h},<2$ weeks). No significant increase in the percentage of G0/G1-phase cells was measured after $24 \mathrm{~h}$ amygdalin treatment in KTC-26 cells. After 2 weeks of amydalin treatment, in KTC-26 cells, concomitant with the S-phase increase, the number of G0/G1-phase cells significantly decreased (Fig. 3), compared to the control.

Amygdalin causes a reduction in cell cycle activating protein expression. We noted that the alterations in cell cycle progression were accompanied by modulation of cell cycle regulating proteins (Fig. 4). In all three cell lines, Caki-1, KTC-26 and A498, treatment with amygdalin for $24 \mathrm{~h}$ and 2 weeks contributed to downregulation of the cell cycle activating proteins cdk1, cdk2 and cdk4 as well as cyclin A and $\mathrm{B}$, with the strongest effects being noted in relation to cdk1 and cyclin B expression. Cyclin D1 was also diminished in 


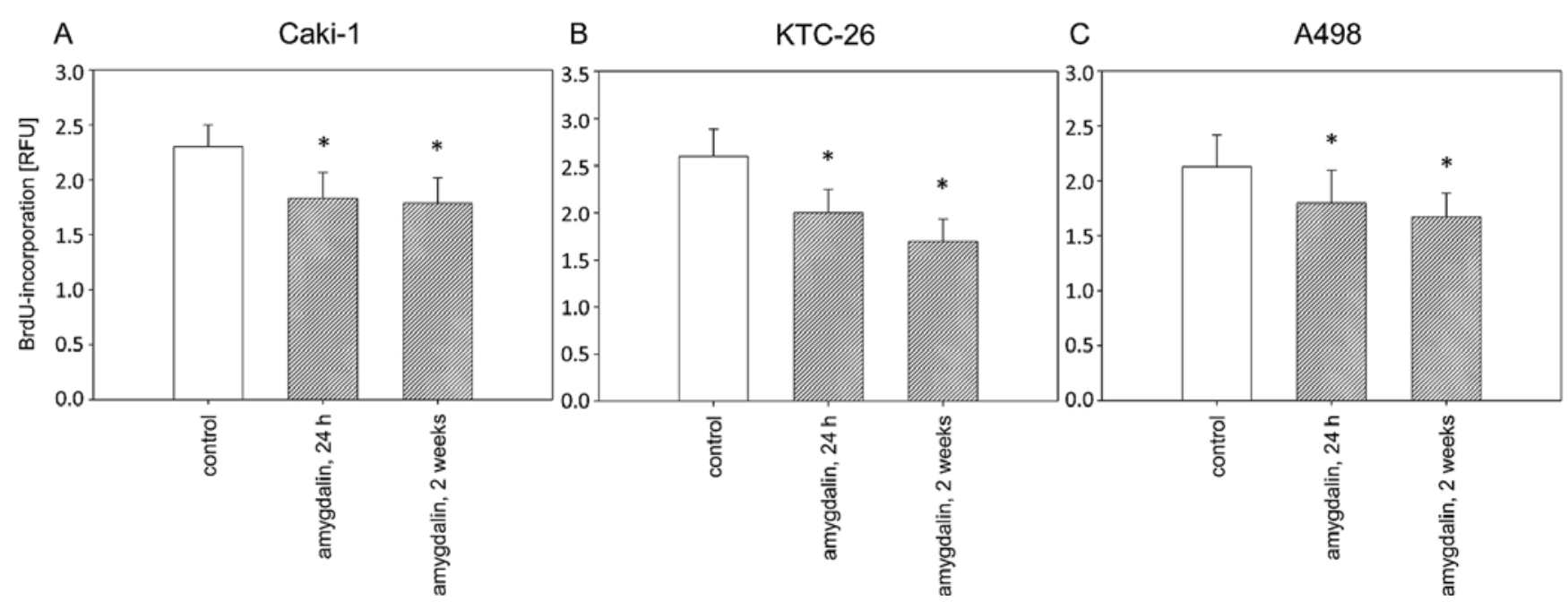

Figure 2. Proliferation of renal cell carcinoma (RCC) cells. (A) Caki-1, (B) KTC-26 and (C) A498 cells were treated with $10 \mathrm{mg} / \mathrm{ml}$ amygdalin for $24 \mathrm{~h}$ or 2 weeks. Controls remained untreated. Bars indicate the means \pm standard deviation (SD). ${ }^{*} \mathrm{p} \leq 0.05$ indicates a significant difference to the control. $\mathrm{n}=5$ experiments.

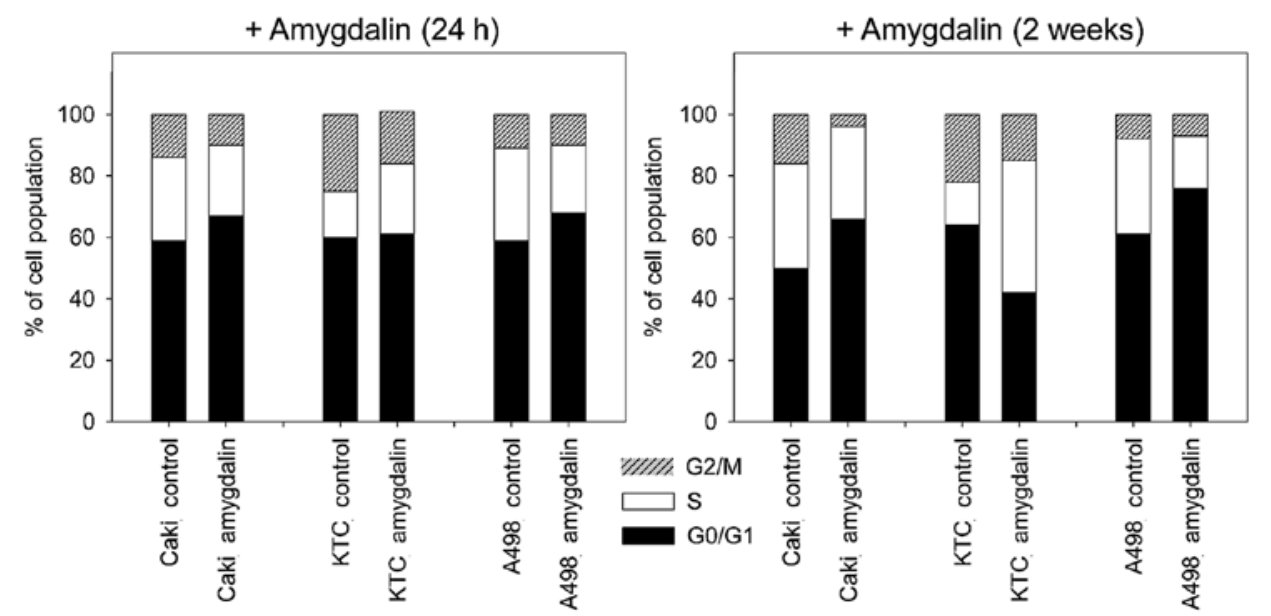

Figure 3. Effect of amygdalin on renal cell carcinoma (RCC) cell distribution in the different cell cycle phases. Percentage of Caki-1 (Caki), KTC-26 (KTC) and A498 cells in G01/1-, S- and G2/M-phases is indicated. RCC cells treated with amygdalin for $24 \mathrm{~h}$ or 2 weeks were compared to untreated controls. One representative of three separate experiments is shown.

Caki-1 and KTC-26 after $24 \mathrm{~h}$ (Fig. 4, left panel) and in Caki-1 and A498 after 2 weeks amygdalin application (Fig. 4, right panel). No marked changes were detectable for cyclin D3, in any cell line. By contrast to the cell cycle activating proteins, expression of the cell cycle inhibiting protein p19 was enhanced after amygdalin exposure in Caki-1 (24 h and 2 weeks) and A498 (24 h) cell lines. p27 was also elevated in A498 cells (24 h) (Fig. 4, left panel). However, p19 and p27 were reduced in KTC-26 cells, and diminished p27 was noted in Caki- 1 cells after $24 \mathrm{~h}$.

A decrease in cdkl and cyclin $B$ is involved in growth inhibition caused by amygdalin. Due to the fact that in the present study the most striking inhibitory effect of amygdalin was noted in relation to cdk1 and cyclin B expression, the impact of those two proteins on tumor cell growth was evaluated by blocking their function using siRNA. Knockdown of cdk1 and cyclin B resulted in significant inhibition of cell growth in all three cell lines, compared to the untreated and mock control (Fig. 5A-C). In all three RCC cell lines, blocking of cdk1 and cyclin B protein expression was verified by western blot analysis (Fig. 5D).

Differentiation markers are modulated by amygdalin treatment. Dedifferentiation of tumor cells is accompanied by loss of E-cadherin and increased $\mathrm{N}$-cadherin expression. Expression of these two differentiation markers was determined in order to evaluate whether amygdalin influences tumor cell differentiation. After $24 \mathrm{~h}$ of treatment with amygdalin, we noted a significant decrease of surface N-cadherin in the three cell lines (Fig. 6). After 2 weeks of amygdalin treatment, markedly increased E-cadherin expression on the surface of Caki-1 and KTC-26 cells was noted (Fig. 6A and B). In KTC-26 cells, E-cadherin elevation was associated with a significant reduction in surface N-cadherin (Fig. 6B). However, $\mathrm{N}$-cadherin expression in Caki-1 cells significantly increased after 2 weeks of amygdalin exposure, although the MFU was still lower than that for E-cadherin (Fig. 6A). No significant effect on E-cadherin was noted in the A498 cells after 2 weeks of amygdalin application. 
$24 \mathrm{~h}$

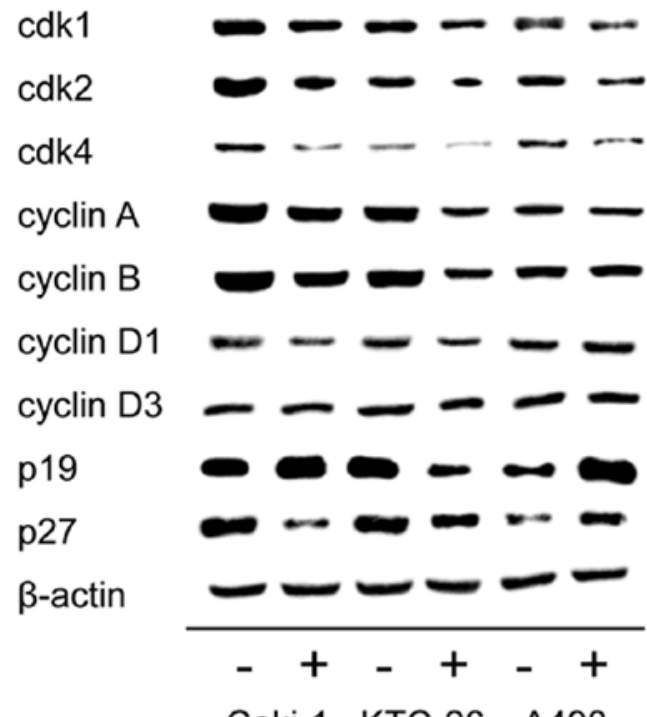

2 weeks

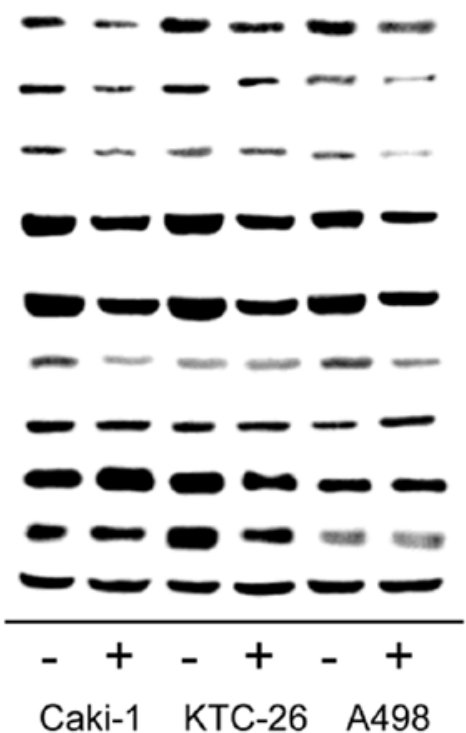

Figure 4. Protein expression profile of cell cycle regulating proteins in renal cell carcinoma (RCC) cells. Caki-1, KTC-26 and A498 cells after $24 \mathrm{~h}$ (left panel) or 2 weeks (right panel) of exposure to amygdalin and untreated controls. -, control; +, amygdalin. $\beta$-actin served as the internal control. One representative of three separate experiments is shown.
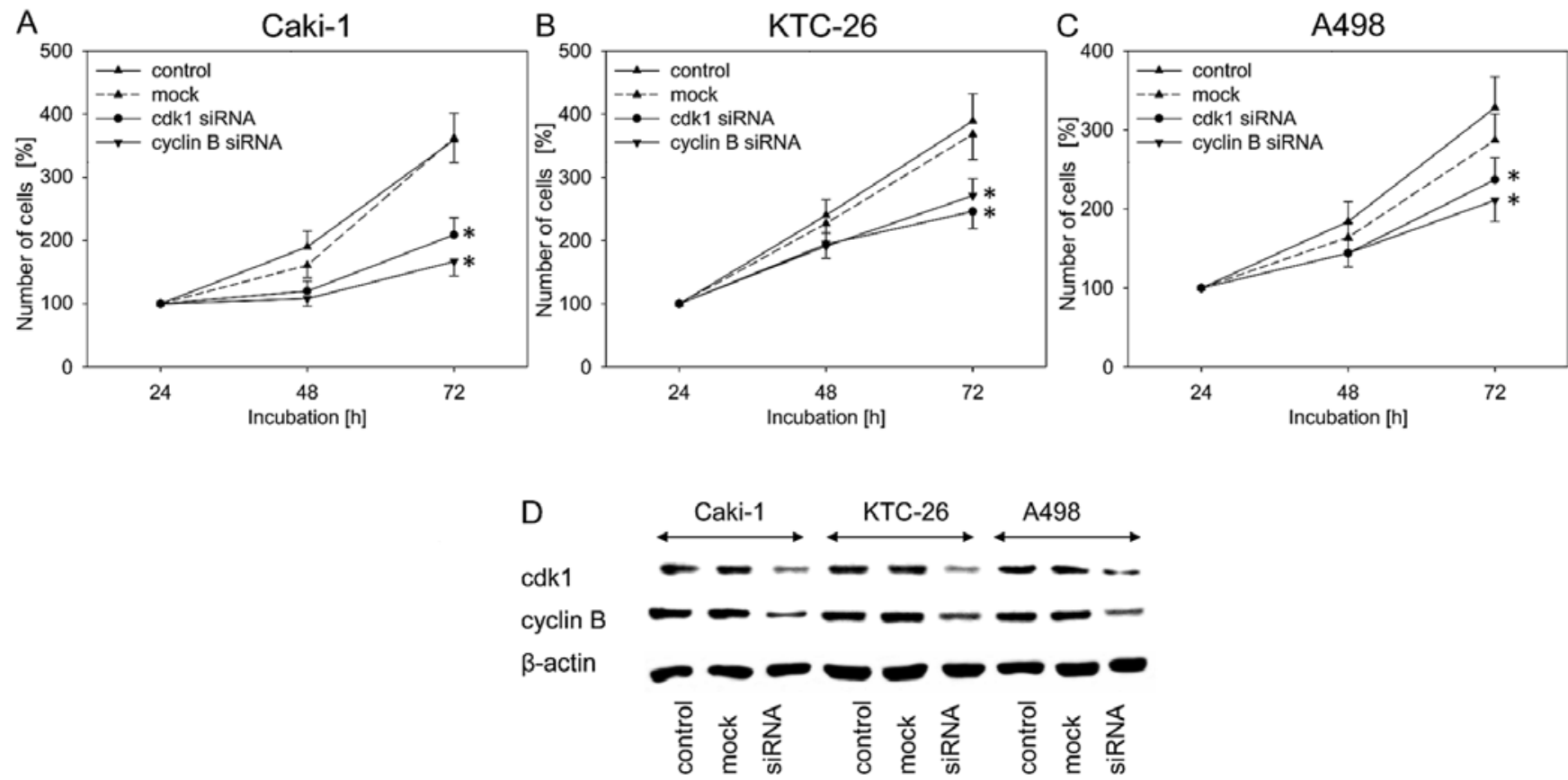

Figure 5. Tumor cell growth of renal cell carcinoma (RCC) cells. (A) Caki-1, (B) KTC-26 and (C) A498 after functional blocking with siRNA targeting cdk1 and cyclin B. AllStars negative control siRNA served as transfection control (mock). Controls remained untreated. Bars indicate standard deviation (SD). " $\mathrm{p} \leq 0.05$, significant difference to the control. $\mathrm{n}=5$ experiments. (D) Protein expression profile of cell cycle regulating proteins of Caki-1, KTC-26 and A498 cells after functional blocking with siRNA targeting cdk1 and cyclin B. AllStars Negative Control siRNA served as transfection control (mock). Controls remained untreated. $\beta$-actin served as the internal control. One representative of three separate experiments is shown.

\section{Discussion}

In the present study, we noted that treatment of the RCC cell lines Caki-1, KTC-26 and A498 with amygdalin caused significant inhibition of cell growth and proliferation. Similar growth reduction after amygdalin application has been noted in non-small cell lung cancer (19) and bladder cancer cells (18) in vitro, as well as cervical cancer cells in vivo (20). Based on our data we conclude that the inhibition of growth induced by amygdalin is not due to apoptosis or necrosis. Other cancer cells such as cervical, bladder and prostate cancer cells react to amygdalin with apoptosis, leading to growth inhibition $(18,20,21)$. Thus, the mode of action of amygdalin seems to depend on the type of cancer. 

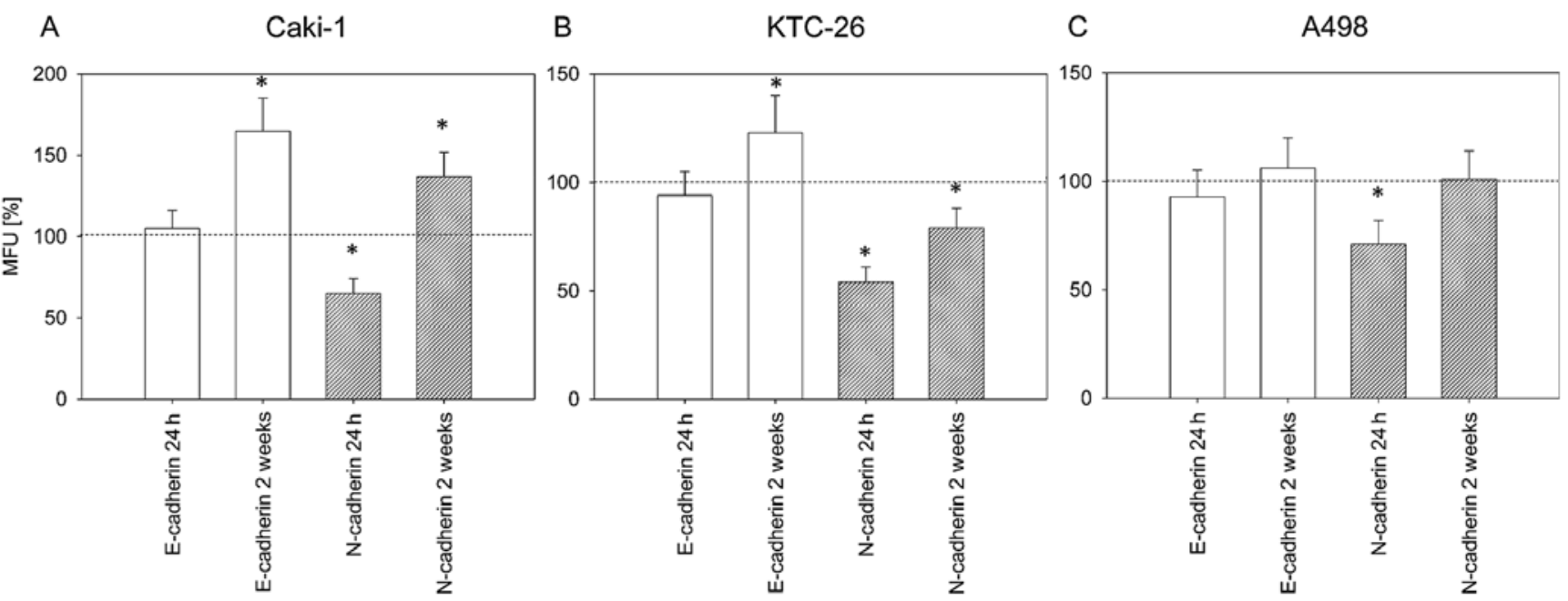

Figure 6. Surface expression of the differentiation markers E- and N-cadherin on renal cell carcinoma (RCC) cells. (A) Caki-1, (B) KTC-26 and (C) A498 cells after $24 \mathrm{~h}$ and 2 weeks of amygdalin application. Surface expression is indicated as mean relative fluorescence units [MFU (\%)]. Controls were set to 100\% (dotted line). Bars indicate the means \pm standard derivation $(\mathrm{SD})$. ${ }^{\mathrm{p}} \mathrm{p} \leq 0.05$ indicates a significant difference to the control. $\mathrm{n}=5$ experiments.

Although inhibition of growth in all three RCC cell lines was accompanied by changes in the percentage of cells in different cell cycle phases, the changes were not homogeneous. Treatment of Caki-1 and A498 cells with amygdalin caused an increase in G0/G1-phase cells by reducing the S- (Caki-1 and A498) and G2/M-phases (Caki-1). Amygdalin treatment caused an increase of S-phase cells in KTC-26 cells, while the G2/M- and G0/G1-phases were reduced after 2 weeks. The elevation of S-phase cells in KTC-26 after amygdalin application is likely indicative of cell cycle arrest in the S-phase. In various bladder cancer cell lines, amygdalin-induced growth blockade, effected by differently influencing cell cycle progression, has also been noted, increasing the percentage of G0/G1 phase cells in one cell line and elevating S-phase cells in another (18).

Alteration of the percentage of cell cycle phases was correlated with modulation of the expression of cell cycle regulating proteins. In all three RCC cell lines, most cell cycle activating proteins were reduced after amygdalin treatment, in particular cdk1 and cyclin B. Cdk1 is known to be a key kinase for mitotic entry (22). The cdk1-cyclin B axis in tumor cells has been shown to be involved in promoting mitosis and overcoming chemotherapy-dependent cell cycle arrest (23). In all three RCC cell lines, the decrease in cdk1 and cyclin B was related to the inhibitory effect exerted by amygdalin, as proved by siRNA knockdown. As well as the cdk1-cyclin B axis, the cdk2-cyclin A axis was also distinctly altered in RCC cells. Cdk2/cyclin A promotes G1/S-phase transition and has been shown to be important to the inhibition of bladder cancer cells caused by amygdalin (18). We suggest that the accumulation of G0/G1-cells was due to the inhibitory effect which amygdalin exerted on cdk2 and cyclin B. However, amygdalin treament of the KTC-26 cell line did not result in G0/G1-, but rather $\mathrm{S}$-phase, arrest. Conceivably, this is due to the cell cycle inhibiting protein $\mathrm{p} 19$, which was elevated in Caki-1 and A498 cells after amygdalin application, but diminished in KTC-26 cells. p19 is involved in G1 checkpoint activity, stopping the entry of cells into the S-phase (24). Inhibiting p19 increases the S-phase cell fraction (25). Thus, this likely explains why we noted an increase in in the G0/G1-phase of Caki-1 and A498 cells, while KTC-26 cells accumulated in the S-phase. Hence, we suggest that amygdalin-induced alterations to cell cycle regulating protein expression are responsible for different effects on cell cycle progression in different cell lines.

During RCC tumor genesis and progression, dedifferentiation accompanied by epithelial mesenchymal transition (EMT) takes place $(26,27)$. During transition the tumor cells lose epithelial (E)-cadherin and gain neural (N)-cadherin $(26,28)$. In all three RCC cell lines used in this study, application of amygdalin for $24 \mathrm{~h}$ caused a significant decrease in N-cadherin expression, which indicates re-differentiation. N-cadherin has previously been associated with aggressiveness and malignant potential of RCC (29). Hence, we suggest that impairing $\mathrm{N}$-cadherin expression with $24 \mathrm{~h}$ of amygdalin application results in a less malignant tumor type. After 2 weeks of amygdalin exposure, a switch in the mode of action of amygdalin became apparent, mainly affecting E-cadherin expression. Caki-1 and KTC-26 E-cadherin surface expression significantly increased. In various RCC cells in vitro epithelial-mesenchymal transition, tumor growth and an aggressive phenotype have been shown to be inversely linked to a low level of E-cadherin $(30,31)$. Poor prognosis and high-grade RCC tumors have been associated with a lack of E-cadherin (32). In human RCC tumor tissue, a 3-fold decrease of E-cadherin has been observed (33), and it has been postulated that E-cadherin expression in RCC is an important predictor for disease recurrence (34). Thus, we suggest that the amygdalin-induced E-cadherin increase in Caki-1 and KTC-26 cells which we noted indicates re-differentiation back to a less aggressive phenotype. The observed switch from $\mathrm{N}$-cadherin reduction to $\mathrm{E}$-cadherin amplification indicates different modes of amygdalin action. Since N-cadherin was no longer diminished in any of the three cell lines after 2 weeks of amygdalin exposure, and was even enhanced in Caki-1 cells, we hypothesize that the ratio between E- and $\mathrm{N}$-cadherin expression is crucial for differentiation status. Indeed, it has been shown that the effect of $\mathrm{N}$-cadherin depends on E-cadherin expression (29). 
In conclusion, amygdalin inhibits cell cycle progression and tumor cell growth in RCC cells, at least partially, by impairing the expression of $\mathrm{cdk} 1$ and cyclin $\mathrm{B}$, thus exerting antitumor effects in vitro. Although no necrotic effects have been detected in vitro, toxic effects caused by the degradation of amygdalin to $\mathrm{HCN}$ are possible, and this aspect requires evaluation. Further investigation using animals is necessary to verify the in vitro effects of amygdalin and to evaluate whether HCN causes cytotoxicity in vivo.

\section{Acknowledgements}

This study was supported by the 'Brigitta und Norbert Muth Stiftung' and 'Prof. Dr. Karl und Gerhard Schiller-Stiftung'.

\section{References}

1. Maute L, Grünwald V, Weikert S, Kube U, Gauler T, Kahl C, Burkholder I and Bergmann L: Therapy of mRCC beyond mTOR-inhibition in clinical practice: results of a retrospective analysis. J Cancer Res Clin Oncol 140: 823-827, 2014.

2. Najjar YG and Rini BI: Novel agents in renal carcinoma: a reality check. Ther Adv Med Oncol 4: 183-194, 2012.

3. Sun M, Thuret R, Abdollah F, Lughezzani G, Schmitges J, Tian Z, Shariat SF, Montorsi F, Patard JJ, Perrotte P and Karakiewicz PI: Age-adjusted incidence, mortality, and survival rates of stage-specific renal cell carcinoma in North America: a trend analysis. Eur Urol 59: 135-141, 2011.

4. Huebner J, Micke O, Muecke R, Buentzel J, Prott FJ, Kleeberg U, Senf B and Muenstedt K; PRIO (Working Group Prevention and Integrative Oncology of the German Cancer Society): User rate of complementary and alternative medicine (CAM) of patients visiting a counseling facility for CAM of a German comprehensive cancer center. Anticancer Res 34: 943-948, 2014.

5. Saghatchian M, Bihan C, Chenailler C, Mazouni C, Dauchy S and Delaloge S: Exploring frontiers: use of complementary and alternative medicine among patients with early-stage breast cancer. Breast 23: 279-285, 2014.

6. Bolarinwa IF, Orfila C and Morgan MR: Determination of amygdalin in apple seeds, fresh apples and processed apple juices. Food Chem 170: 437-442, 2015.

7. Tanaka R, Nitta A and Nagatsu A: Application of a quantitative 1H-NMR method for the determination of amygdalin in Persicae semen, Armeniacae semen, and Mume fructus. J Nat Med 68 : 225-230, 2014

8. Lee J, Zhang G, Wood E, Rogel Castillo C and Mitchell AE: Quantification of amygdalin in nonbitter, semibitter, and bitter almonds (Prunus dulcis) by UHPLC-(ESI)QqQ MS/MS. J Agric Food Chem 61: 7754-7759, 2013.

9. Moss RW: The laetrile controversy. In: The Cancer Industry. The Classic Expose on the Cancer Establishment. First Equinox Press, Brooklyn, NY, pp131-152, 1996.

10. Curt GA: Unsound methods of cancer treatment. Princ Pract Oncol Updates 4: 1-10, 1990.

11. PDQ Cancer Complementary and Alternative Medicine Editorial Board. Laetrile/Amygdalin $\left(\mathrm{PDQ}^{\circledR}\right)$ : Health Professional Version. PDQ Cancer Information Summaries [Internet]. Bethesda (MD): National Cancer Institute (US); 2002-2015.

12. Moss RW: Patient perspectives: Tijuana cancer clinics in the post-NAFTA era. Integr Cancer Ther 4: 65-86, 2005.

13. Moertel CG, Fleming TR, Rubin J, Kvols LK, Sarna G, Koch R, Currie VE, Young CW, Jones SE and Davignon JP: A clinical trial of amygdalin (Laetrile) in the treatment of human cancer. N Engl J Med 306: 201-206, 1982.

14. Moertel CG, Ames MM, Kovach JS, Moyer TP, Rubin JR and Tinker JH: A pharmacologic and toxicological study of amygdalin. JAMA 245: 591-594, 1981.

15. Ames MM, Moyer TP, Kovach JS, Moertel CG and Rubin J: Pharmacology of amygdalin (laetrile) in cancer patients. Cancer Chemother Pharmacol 6: 51-57, 1981.
16. Newell GR and Ellison NM: Ethics and designs: laetrile trials as an example. Cancer Treat Rep 64: 363-365, 1980.

17. Wahab MF, Breitbach ZS, Armstrong DW, Strattan R and Berthod A: Problems and pitfalls in the analysis of amygdalin and its epimer. J Agric Food Chem 63: 8966-8973, 2015.

18. Makarević J, Rutz J, Juengel E, Kaulfuss S, Reiter M, Tsaur I, Bartsch G, Haferkamp A and Blaheta RA: Amygdalin blocks bladder cancer cell growth in vitro by diminishing cyclin A and cdk2. PLoS One 9: e105590, 2014.

19. Qian L, Xie B, Wang Y and Qian J: Amygdalin-mediated inhibition of non-small cell lung cancer cell invasion in vitro. Int J Clin Exp Pathol 8: 5363-5370, 2015.

20. Chen Y, Ma J, Wang F, Hu J, Cui A, Wei C, Yang Q and Li F: Amygdalin induces apoptosis in human cervical cancer cell line HeLa cells. Immunopharmacol Immunotoxicol 35: 43-51, 2013.

21. Chang HK, Shin MS, Yang HY, Lee JW, Kim YS, Lee MH, Kim J, Kim KH and Kim CJ: Amygdalin induces apoptosis through regulation of $\mathrm{Bax}$ and $\mathrm{Bcl}-2$ expressions in human DU145 and LNCaP prostate cancer cells. Biol Pharm Bull 29: 1597-1602, 2006.

22. Chang WL, Yu CC, Chen CS and Guh JH: Tubulin-binding agents down-regulate matrix metalloproteinase-2 and -9 in human hormone-refractory prostate cancer cells - a critical role of Cdk1 in mitotic entry. Biochem Pharmacol 94: 12-21, 2015.

23. Visconti R, Della Monica R, Palazzo L, D'Alessio F, Raia M, Improta S, Villa MR, Del Vecchio L and Grieco D: The Fcp1-Wee1-Cdk1 axis affects spindle assembly checkpoint robustness and sensitivity to antimicrotubule cancer drugs. Cell Death Differ 22: 1551-1560, 2015.

24. Wang WT, Catto JW and Meuth M: Differential response of normal and malignant urothelial cells to CHK1 and ATM inhibitors. Oncogene 34: 2887-2896, 2015.

25. Carcagno AL, Marazita MC, Ogara MF, Ceruti JM, Sonzogni SV, Scassa ME, Giono LE and Cánepa ET: E2F1-mediated upregulation of p19INK4d determines its periodic expression during cell cycle and regulates cellular proliferation. PLoS One 6: e21938, 2011.

26. Yuan H, Meng X, Guo W, Cai P, Li W, Li Q, Wang W, Sun Y, $\mathrm{Xu} \mathrm{Q}$ and $\mathrm{Gu}$ Y: Transmembrane-bound IL-15-promoted epithelial-mesenchymal transition in renal cancer cells requires the Src-dependent Akt/GSK-3 $\beta / \beta$-catenin pathway. Neoplasia 17: 410-420, 2015.

27. He H and Magi-Galluzzi C: Epithelial-to-mesenchymal transition in renal neoplasms. Adv Anat Pathol 21: 174-180, 2014.

28. Zhang X, Ren J, Yan L, Tang Y, Zhang W, Li D, Zang Y, Kong $\mathrm{F}$ and $\mathrm{Xu} \mathrm{Z}$ : Cytoplasmic expression of pontin in renal cell carcinoma correlates with tumor invasion, metastasis and patients' survival. PLoS One 10: e0118659, 2015.

29. Shimazui T, Kojima T, Onozawa M, Suzuki M, Asano T and Akaza $\mathrm{H}$ : Expression profile of $\mathrm{N}$-cadherin differs from other classical cadherins as a prognostic marker in renal cell carcinoma. Oncol Rep 15: 1181-1184, 2006.

30. Cheng C, Wan F, Liu L, Zeng F, Xing S, Wu X, Chen X and Zhu Z: Overexpression of SATB1 is associated with biologic behavior in human renal cell carcinoma. PLoS One 9: e97406, 2014.

31. Huang J, Yao X, Zhang J, Dong B, Chen Q, Xue W, Liu D and Huang Y: Hypoxia-induced downregulation of miR-30c promotes epithelial-mesenchymal transition in human renal cell carcinoma. Cancer Sci 104: 1609-1617, 2013.

32. Gervais ML, Henry PC, Saravanan A, Burry TN, Gallie BL, Jewett MA, Hill RP, Evans AJ and Ohh M: Nuclear E-cadherin and VHL immunoreactivity are prognostic indicators of clear-cell renal cell carcinoma. Lab Invest 87: 1252-1264, 2007.

33. Ho MY, Tang SJ, Chuang MJ, Cha TL, Li JY, Sun GH and Sun KH: TNF- $\alpha$ induces epithelial-mesenchymal transition of renal cell carcinoma cells via a GSK3 $\beta$-dependent mechanism. Mol Cancer Res 10: 1109-1119, 2012.

34. Harada K, Miyake H, Kusuda Y and Fujisawa M: Expression of epithelial-mesenchymal transition markers in renal cell carcinoma: impact on prognostic outcomes in patients undergoing radical nephrectomy. BJU Int 110: E1131-E1137, 2012. 